\title{
INFLUENCE OF DYNAMIC NON-EQUILIBRIUM PROCESSES ON STRENGTH AND PLASTICITY OF MATERIALS OF TRANSPORTATION SYSTEMS
}

\author{
Mykola Chausov ${ }^{1}$, Andriy Pylypenko ${ }^{2}$, Valentyn Berezin ${ }^{3}$, Kateryna Volyanska ${ }^{4}$, \\ Pavlo Maruschak ${ }^{5}$, Volodymyr Hutsaylyuk ${ }^{6}$, Lyudmila Markashova ${ }^{7}$, \\ Stanislav Nedoseka ${ }^{8}$, Abdellah Menou ${ }^{9}$ \\ ${ }^{1-4}$ Dept of Mechanics, National University of Life and Environmental Sciences \\ of Ukraine, Kyiv, Ukraine \\ ${ }^{5}$ Dept of Industrial Automation, Ternopil Ivan Puluj National Technical University, Ternopil, Ukraine \\ ${ }^{6}$ Dept of Machine Design, Military University of Technology, Warsaw, Poland \\ ${ }^{7,8}$ Dept of Physical and Chemical Research of Materials, E. O. Paton Electric Welding Institute \\ of the National Academy of Sciences of Ukraine, Kyiv, Ukraine \\ ${ }^{9}$ International Academy of Civil Aviation, Casablanca, Morocco
}

Submitted 23 August 2015; resubmitted 6 July 2016; accepted 15 September 2016; published online 10 May 2017

\begin{abstract}
New experimental results on the effect of additional force impulse loading on the variation of the initial structure of the aircraft material (alloys D16, 2024-T3, VT22) at various stages of deformation are presented and a significant enhancement of its initial plasticity is achieved. Complex investigations into the material properties after a dynamic non-equilibrium process made it possible to describe the main regularities in the nature of deformation and fracture of materials, which allowed proposing general recommendations on using the revealed physical and mechanical regularities in the evaluation of strength of aircraft structures.
\end{abstract}

Keywords: aircraft material; deformation; fracture; strength of aircraft structures; failure analysis.

\section{Introduction}

An indispensable component of aircraft construction is the performance of endurance field tests and laboratory tests of structural elements and materials (Starke, Staley 1996; Ostash et al. 2006). Structural materials used in the production of planting of the aircraft fuselage should be resistant to depletion of plasticity and aging (Merati 2005). The same is true about the need to ensure durability (taking into account plastic qualities and strength of materials) of rocket and aircraft structures, as well as chemical, petrochemical and transport structures, operated under heavy influences of different physical nature, including local loads and contact interactions (Merati 2005; Smith et al. 2000; Lo et al. 2009).

Therefore, the development of new methods for enhancing the mechanical properties of materials is very important. One of them is the modification of their properties using additional force impulse loading, and the implementation of Dynamic Non-equilibrium Processes (DNP) (Zasimchuk et al. 2009; Chausov et al. 2015a).

In DNP, the interaction of structural elements of materials with energy fields causes self-organized process in materials, leading to the formation of new spacedissipative structures that cause significant changes in the initial mechanical properties of materials.

In this case, the essential parameters of the DNP process are time and speed of the energy introduction into the material. As it was shown earlier (Zasimchuk et al. 2009; Chausov et al. 2015a), under additional force impulse loading of materials, with the preset speed and frequency of loading (in particular, the preset range of loading is $1-601 / \mathrm{sec}$, and the preset range of loading frequencies is $1-2 \mathrm{kHz}$ ), structural reorganization begins

A preliminary version of this paper was presented at the 4th International Conference 'In-Service Damage of Materials, its Diagnostics and Prediction' on 21-24 of September 2015 (Ternopil, Ukraine). 
in materials, which is due to variation of the energy exchange mode in the medium, when the medium absorbs the impulse brought by the impulse wave, but has not enough time to pass it directly to the microscopic level and transform heat energy.

Thus, there is a situation when a large part of the energy from the additional impulse loading is transmitted not to the microscopic level, but to some intermediate mesoscopic level, where it is spent on the structural reorganization and heterogenization of the material (Khantuleva, Meshcheryakov 2016).

This mode of processing allows obtaining a number of specific properties of the material, which manifest themselves, first of all, in a significant plastification due to the formation of dissipative structures with the preservation of strength properties (Chausov et al. 2015b). This is associated with self-organization mechanisms of the material structure in case of a sudden variation of action of the external force.

A number of works are known, which describe individual aspects of the material self-organization under additional impulse loading and DNP (Hutsaylyuk et al. $2013,2014)$. There have been some attempts to describe mathematically the processes of self-organization of the material surface, predict the formation of topography on the surface, which occurs due to morphological changes in the material (Lytvynenko, Maruschak 2015). However, most of these works consider simplified conditions of deformation or other groups of materials (Chausov et al. 2012; Lebedev, Chausov 2004). This suggests that, on the whole, insufficient attention has been given to the comprehensive study of the problem of the DNP in the materials used in transport and petrochemical machine building.

This necessitates the analysis of strain localization processes, systematization of the DNP influence on the properties of materials of transport systems. Also important is the establishment of interconnection between transient changes in the temperature and force modes of specimen loading, and the methods of additional treatment of specimens with cold, taking into account their influence on the material characteristics and physical interpretation of the revealed effects. The practical value of such approaches is that the results obtained can be used for further development of the theory of weakening environments in the development of methods for the modification of structural materials of aircrafts and spaceships. This will allow using the effect of plastification to ensure a more complete use of the existing resource and create the additional resource of the materials of transport systems, which, in turn, will enhance the structural reliability (Lebedev, Chausov 2004).

The objective of this work is to reveal characteristic changes in the structures of materials of different classes after the DNP implementation, using new methods, and systematize additional force loading to ensure maximum increase in the initial plasticity.

Aircraft materials. In this paper, the most common groups of materials for the production of aircrafts are considered (Gantois, Morris 2004; Kaufmann 2008), Fig. 1. Although there is a tendency for a widespread use of composite materials in aircraft production, a significant part of present-day aircrafts is made of metallic materials. There is a problem of improving the structural characteristics and durability (Jones et al. 2005; Warren 2004), Fig. 1. Decreasing the material damageability, increasing its durability, and reducing the number of defects can significantly lower the cost of the aircraft maintenance. Aluminum and titanium alloys are traditional aircraft materials, but with the emergence of composite materials with similar mechanical properties, their use has declined slightly.

\section{Research Technique}

The objects of research were the materials of transport systems, in particular:

- Alloy D16 (GOST 4784-97, Al = 90.9-94.7\%; $\mathrm{Cu}=3.8-4.9 \% ; \mathrm{Mg}=1.2-1.8 \%$; Fe and $\mathrm{Si} \leq 0.5 \%$; $\mathrm{Mn}=0.3-0.9 \% ; \mathrm{Cr} \leq 0.1 \% ; \mathrm{Ti} \leq 0.15 \% ; \mathrm{Zn} \leq$ $0.25 \%$; admixture $\leq 0.15 \%$ ), used in the production of plating, framing, stringers, longerons of

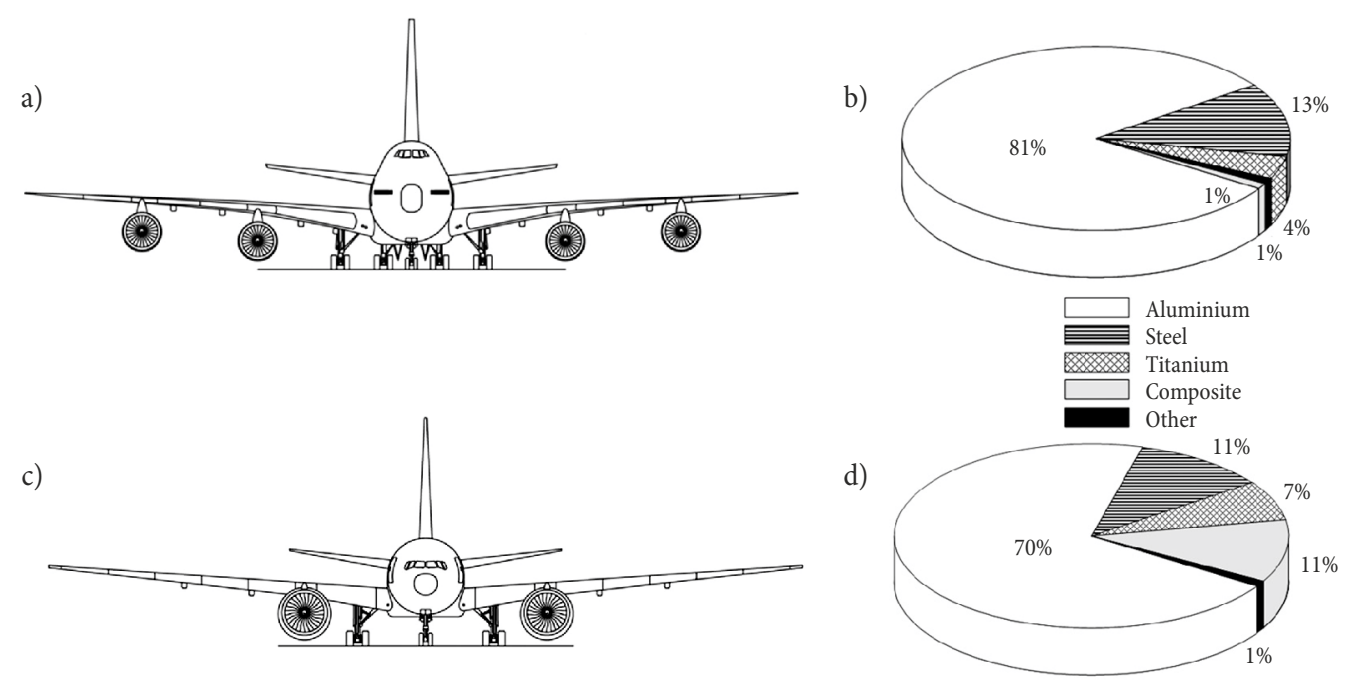

Fig. 1. Combination of materials used in Boeing aircrafts: a, b - Boeing-747; c, d - Boeing-777 (Dursun, Soutis 2014; Jones et al. 2005) 
aircrafts and car bodies (Ostash et al. 2006; Lebedev, Chausov 2004);

- Alloy 2024-T3 (ASTM B209-14, Cu = 4.35\%; $\mathrm{Mg}=1.50 \% ; \mathrm{Fe}=0.50 \% ; \mathrm{Si}=0.50 \% ; \mathrm{Zn}=0.25 \%$; $\mathrm{Ti}=0.15 \% ; \mathrm{Cr}=0.10 \%$; others $\leq 0.20)$, which is widely used for the outer covering, in particular, of civil aircraft fuselages (Merati 2005; Smith et al. 2000);

- Alloy VT22 (GOST 19807-91, Fe = 0.5-1.5\%; $\mathrm{C}=$ up to $0.1 \% ; \mathrm{Si} \leq 0.15 \% ; \mathrm{Cr}=0.5-1.5 \% ; \mathrm{Mo}=$ $4-5.5 \% ; \mathrm{V}=4-5.5 \% ; \mathrm{N} \leq 0.05 \% ; \mathrm{Ti}=79.4-86.3 \%$; $\mathrm{Al}=4.4 \% ; \mathrm{Zr} \leq 0.3 \% ; \mathrm{O} \leq 0.18 \% ; \mathrm{H} \leq 0.015 \%$; others $\leq 0.3 \%$ ), which is traditionally used for the production of vital components of the airframe and chassis of the passenger and heavy transport aircrafts, in particular, Il-96T, Il-114 (Shakleina, Zamyatin 2010; Moiseev 2000; Zherebtsov 2012); these alloys ensure reliability of aircrafts, a reduction in their mass, and a long service life of their vital components operated under complex modes of loading (tension, bending, etc.);

- Another test material was steel 04Kh18N10 (GOST 5632-72, C $\leq 0.04 \%$; $\mathrm{Si} \leq 0.8 \%$; $\mathrm{Mn} \leq$ $2 \%$; $\mathrm{Ni}=9-11 \% ; \mathrm{S} \leq 0.02 \% ; \mathrm{P} \leq 0.035 \%$; $\mathrm{Cr}=$ $17-19 \%)$, which is used in the production of seamless pipes for chemical and petrochemical industry (Lo et al. 2009; Zholud et al. 2012).

In this work, a choice of test materials was preconditioned by a need to compare the kinetics of deformation fields of materials with a pronounced wave process of plastic deformation - aluminum alloys D16 and 2024-T3, and materials with relatively uniform and proportional process of plastic deformation - titanium alloy VT22 and stainless steel 04Kh18N10.

Investigations were carried out on specimens from plastic sheet materials with a thickness of 1.5 and $3 \mathrm{~mm}$ and a width of 10.2 and $25 \mathrm{~mm}$. The gauge length of specimens varied from 18.5 to $75 \mathrm{~mm}$ depending on the selected width.

Specimens of the material were tested on the ZD$100 \mathrm{Pu}$ modified hydraulic setup for static tests. The modified version of the setup consists of two contours the external (load frame of the setup) and the internal ones, respectively. The internal contour represents the simplest statically undetermined structure in the form of three parallel elements, which are loaded simultaneously - the central specimen and two symmetrical satellite specimens ('brittle samples') of different cross-section, prepared from tampered steels 65 G or U8-U12. During loading of this structure, satellite specimens get broken (under preset loading or deformation), and the impulse introduction of energy into the material of the test specimen is performed at the frequency of $1-2 \mathrm{kHz}$ (Fig. 2).

By changing the load that is necessary for the specimens-satellites failure (given high force impulse) and changing the degree of prior static of the materials sample at which the short-term loadings are performed $(15-45 \mathrm{~ms})$, it is possible to study the effect of these parameters on the subsequent mechanical behaviour of the material specimens until its fracture.

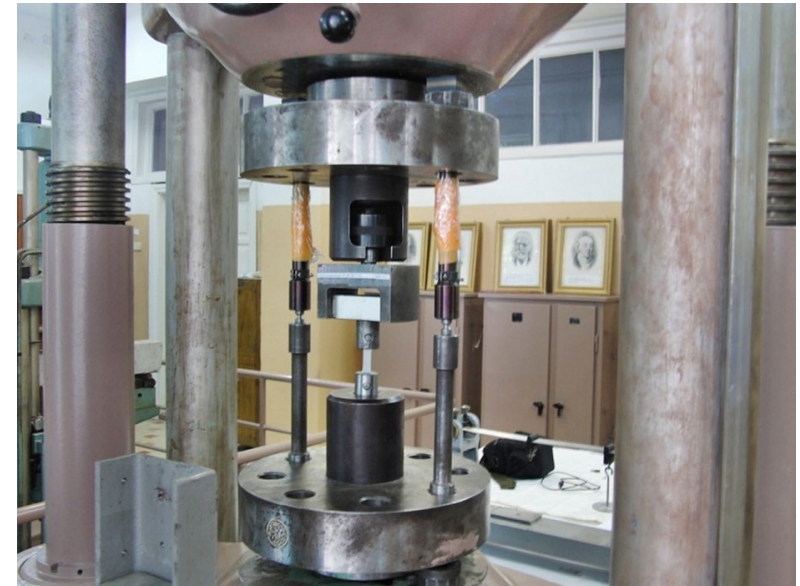

Fig. 2. General view of the inner-contour of the loading system

Moreover, with a view to localization of the dissipative structure, a special methodology was used with regard to the gauge length of the test specimen, which consisted in the application and drying of the concentrated colloid solution of tungsten nanoparticles on the separate gauge length of specimens (Chausov, Volianska 2011).

To investigate fracture toughness in the gauge length of specimens with a width of $20 \mathrm{~mm}$, an opening with diameter of $1.4 \mathrm{~mm}$ was made in the middle and then a 'natural' macrocrack of preset size was 'grown' in the zone of concentrator for further Static Tensioning (ST) and the DNP. The colloid solution was also applied to the crack tip and in the zone of its potential propagation in accordance with the above technique. Specimens with cracks were tested using the method of complete curves, which provided for the stability of the processes of deformation and fracture at different stages, including at the stage of macrofracture (Lebedev et al. 1996; Lebedev, Chausov 2004).

The Acoustic Emission (AE) method was also used, which consists in scanning by contemporary AE devices EMA-3 (Vasyl'jev et al. 2012) in a special temperature mode of loading (Holding specimens in the medium of Liquid Nitrogen (HLN) after the DNP implementation at a room temperature) for the evaluation of the nonuniformity of the mechanical properties of materials after the formation of dissipative structures.

\section{Metal Properties}

\subsection{Aluminum Alloys D16 and 2024-T3}

In case of one-time impulse loading of materials, there are two main factors, which have a significant effect on the variation of the mechanical properties of materials under subsequent ST:

- the level of the preliminary static deformation, at which impulse force loading was performed, and the amplitude of loading;

- the effect of variation of the temperature mode of loading. 
In fact, depending on the values of these factors, a multitude of new mechanical conditions of the material may occur under the DNP. Therefore, it is important to know when the mechanical properties of the material improve to the maximum, and when they worsen to the maximum. At first, the structure of the material after the DNP at a room temperature was 'frozen' in the medium of liquid nitrogen. After warming at a room temperature, the specimens were subjected to static loading again, and their work to embrittlement was evaluated.

Alloy D16. Typical stress-strain curves of aluminum alloy D16 subjected to static deformation by the scheme ST + DNP + ST are given in Fig. 3. One of the main effects associated with the influence of the DNP on aluminum alloy D16 is the formation of the yield plateau, whose length can be regulated by the initial conditions of additional force loading. If the initial plasticity of aluminum alloy D16 was $14 \%$, the length of such plateau in the alloy reached $10-12 \%$ (Fig. 3) in our investigations, indicating a significant influence of the DNP on the enhancement of the general plasticity of alloy D16.

Alloy 2024-T3. In the course of previous investigations of specimens from alloy 2024-T3 (Zasimchuk et al. 2009), the deformation of alloys 2024-T3 and D16 was found to be similar under the DNP. Let us consider the effect of different test patterns on the regularities in the deformation of alloy 2024-T3 (Fig. 4):

- HLN, warming up to $20^{\circ} \mathrm{C}+\mathrm{ST}$ (curve 2, Fig. 4) has practically no effect on the mechanical properties of alloy 2024-T3;

- ST + DNP $\left(F_{i m p}=90.4 \mathrm{kN}\right)$, HLN, warming up to $20^{\circ} \mathrm{C}+\mathrm{ST}$ does not lead to an improvement of the mechanical properties of the material (curve 3), since damage or defects that appeared during the DNP does not disappear, causing a depletion of the material plasticity;

- ST + DNP $\left(F_{i m p}=111.8 \mathrm{kN}\right)$, HLN, warming up to $20^{\circ} \mathrm{C}+\mathrm{ST}$ also deteriorates the mechanical properties of the material (curve 4, Fig. 4).

- It should be noted that under the above modes of loading, specimens got broken practically in the quasi-brittle manner (curve 4, Fig. 4).

Thus, it is proven experimentally that self-organization of structures of aluminum alloys at a room temperature due to additional force loading leads to a significant increase in plasticity (up to 60-70\%), practically without any depletion of strength of the alloy 2024-T3.

However, with a decrease in temperature, a newly created dissipative structure of aluminum alloys used in aviation is prone to embrittlement, which should be taken into account in operation of real products. Therefore, it is important to consider the influence of additional compressive temperature stresses on an increase in the volume of damage in the dissipative structure.

The obtained experimental results indicate that the volume of the newly formed dissipative structure in the material should be referred to one of the key parameters, which have a significant effect on the variation of the mechanical properties during the repeated ST (Zasimchuk et al. 2009; Hutsaylyuk et al. 2014).

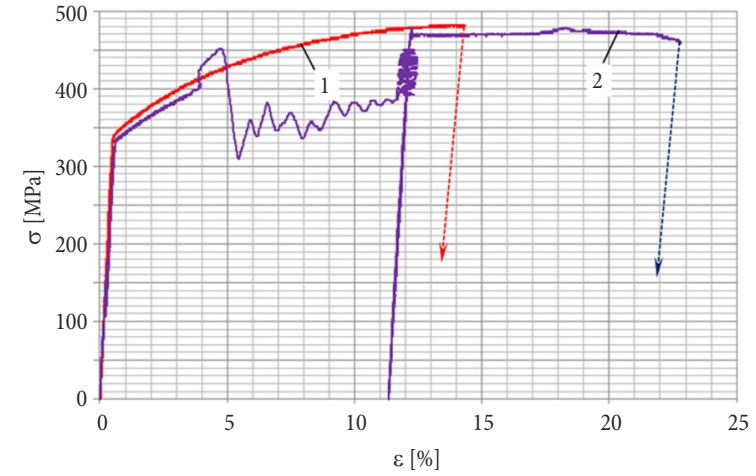

Fig. 3. Stress-strain curves of aluminum alloy D16: $1-\mathrm{ST} ; 2-\mathrm{ST}+\mathrm{DNP}\left(F_{i m p}=89.6 \mathrm{kN}\right)+\mathrm{ST}$

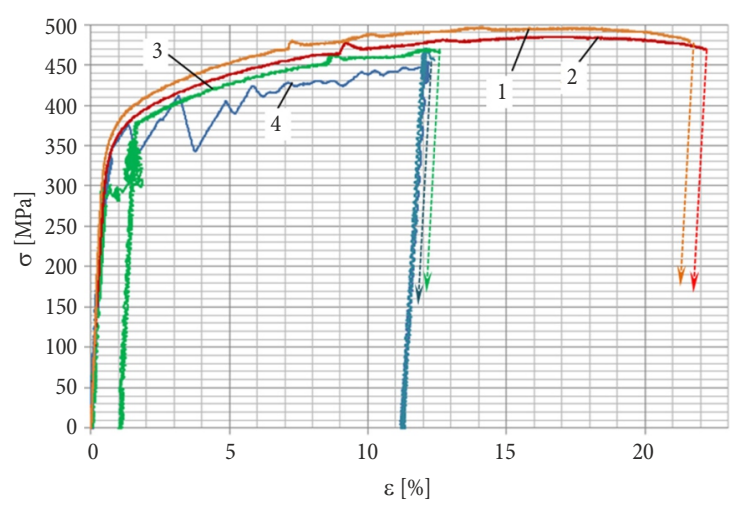

Fig. 4. Stress-strain curve of aluminum alloy 2024-T3: 1 - ST at $20^{\circ} \mathrm{C} ; 2-\mathrm{HLN}$, warming up to $20^{\circ} \mathrm{C}+\mathrm{ST} ; 3-\mathrm{ST}+\mathrm{DNP}$ $\left(F_{i m p}=90.4 \mathrm{kN}\right), \mathrm{HLN}$, warming up to $20^{\circ} \mathrm{C}+\mathrm{ST} ; 4-\mathrm{ST}+$

DNP $\left(F_{i m p}=111.8 \mathrm{kN}\right), \mathrm{HLN}$, warming up to $20^{\circ} \mathrm{C}+\mathrm{ST}$

We should also note a stable, although insignificant decrease in strength by $\sim 10-30 \mathrm{MPa}$ in aluminum alloy D16 after the DNP. In this case, a decrease in strength of the alloy 2024-T3 is not observed. The fact that an increase in the material plasticity after the DNP implementation is associated with the structural self-organization was time and again proved by the authors using direct physical methods of research (Zasimchuk et al. 2009; Hutsaylyuk et al. 2013, 2014; Chausov et al. $2015 b, 2012)$. In case of the DNP implementation in the plastic area of the material deformation, self-organization occurs in the form of newly formed finely banded structures interconnected at different structural levels. Moreover, the density of these structures is less than that of the base material.

\subsection{Stainless Steel $04 \mathrm{Kh} 18 \mathrm{~N} 10$}

The DNP implementation in the plastic area of stainless steel also leads to the formation of spatial narrowbanded dissipative structures (Chausov, Volianska 2011). The DNP implementation under initially low strain was chosen specifically to decrease the influence of the material damage on the process character. Fig. 5 shows the experimental results in the case when impulse loading was applied practically within the elastic section of deformation. The results were obtained in accordance 
with the technique, which allows localizing the dissipative structure on the preset gauge length of the specimen (Chausov, Volianska 2011).

Two sequential impulse loads (DNP) were implemented, and, additionally, a change in the temperature mode of loading (after each impulse loading, specimens were held for 1 hour in the medium of liquid nitrogen). Under the above complex preliminary mode of loading during the repeated ST of the specimen at a room temperature, the test steel moved to the yield plateau with the length of more than $14 \%$ (curve 1, Fig. 5) practically immediately. However, the manifestation of such a specific plastic behaviour of the steel leads to a noticeable decrease in its general plasticity as compared to the initial condition (curve 2, Fig. 5). As is seen, the yield point of the material increases after the DNP, and the material hardens (Fig. 5). Under such conditions, the metal grains change their orientation in the direction of force application, a resistance to deformation increases, and the plasticity of the steel decreases. The experiments with stainless steel confirm previous results obtained for aluminum alloys, according to which a dissipative structure formed at a room temperature becomes brittle during its subsequent tensioning at a low temperature, the effect of which must be taken into account while constructing the models of material behaviour under such complex modes of loading and evaluating safety margins.

Fig. 6 shows some characteristic experimental results for the embrittlement of dissipative structures in stainless steels after HLN for one hour. In the process of investigations, a significant influence of deformation hardening on the variation of the mechanical properties of stainless steel $04 \mathrm{Kh} 18 \mathrm{~N} 10$ during subsequent ST was observed.

The analysis of curves (Fig. 6) shows that the complex mode of loading of steel $04 \mathrm{Kh} 18 \mathrm{~N} 10$ does not lead to an improvement of the mechanical properties of the material, since positive qualities of the dissipative structure disappear due to relaxation, but damage or defects obtained after the DNP remain.

Let us consider the effect of the DNP on fracture toughness of steel $04 \mathrm{Kh} 18 \mathrm{~N} 10$ (Fig. 7). The results obtained indicate a possibility to enhance fracture toughness of materials after the DNP within the local area in the vicinity of the macrocrack tip.

Attention should be paid to (curve 1, Fig. 7), which corresponds to the self-pressing growth of a macrocrack from the initial concentrator in the form of an opening. A slope of this curve at the stage of growth of a macrocrack (section I) characterizes energy expenditures on the macrocrack propagation across the width of the sheet steel. A complete unloading of the specimen at a preset length of the macrocrack and impulse loading up to point $\mathrm{K}$ in curve 2 increases energy expenditures on the growth of a macrocrack significantly (the dashed part in Fig. 7). Even greater energy expenditures on the growth of a macrocrack were achieved when concentrated colloid solution of nanoparticles was applied to the macrocrack tip and to the zone of its propagation prior to impulse loading (curve 3, Fig. 7).

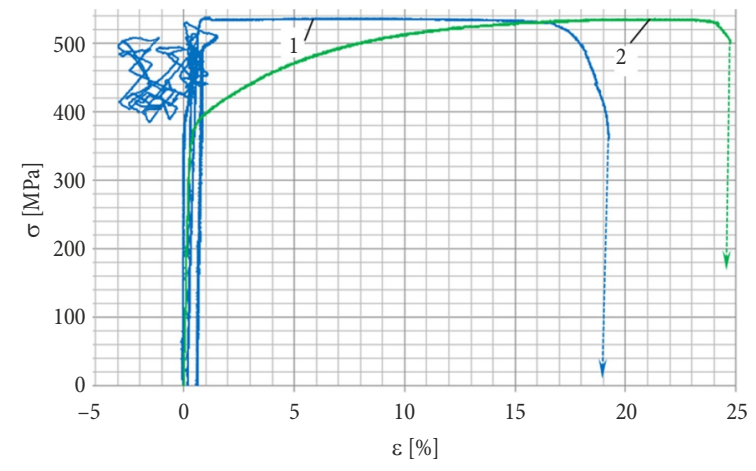

Fig. 5. Stress-strain curves for stainless steel 04Kh18N10: $1-\mathrm{ST}+\mathrm{DNP}\left(F_{i m p}=103.9 \mathrm{kN}\right)+\mathrm{HLN}+\mathrm{DNP}\left(F_{i m p}=\right.$ $109.3 \mathrm{kN})+\mathrm{HLN}+\mathrm{ST} ; 2-\mathrm{ST}$

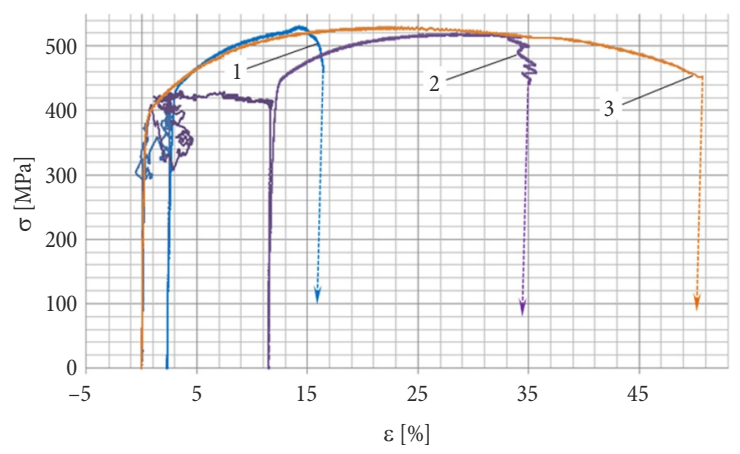

Fig. 6. Stress-strain curve for stainless steel 04Kh18N10: 1 $\operatorname{DNP}\left(F_{i m p}=68.5 \mathrm{kN}\right)+\mathrm{ST} ; 2-\mathrm{HLN}+\operatorname{DNP}\left(F_{i m p}=59.9 \mathrm{kN}\right)+$ ST; 3 - ST in the initial condition at $t=20^{\circ} \mathrm{C}$

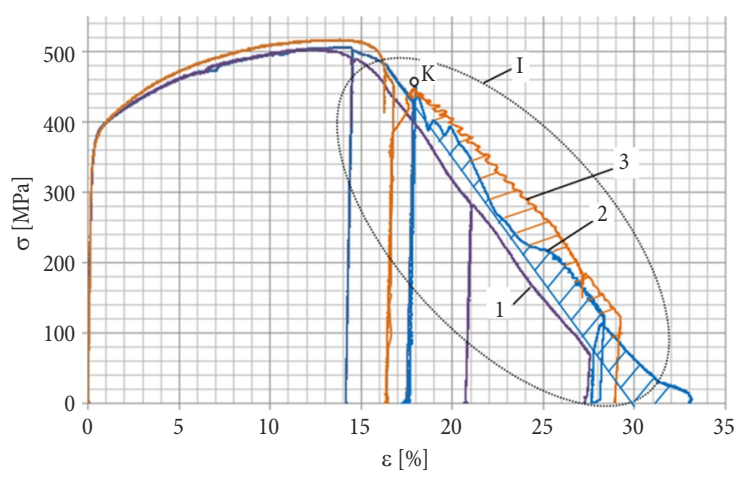

Fig. 7. Curves of macrocrack growth in specimens from stainless steel $04 \mathrm{Kh} 18 \mathrm{~N} 10$ with openings: $1-\mathrm{ST}, 2-\mathrm{ST}+$ $\operatorname{DNP}\left(F_{i m p}=7.4 \mathrm{kN}\right) ; 3-\mathrm{ST}+\mathrm{DNP}\left(F_{i m p}=12.7 \mathrm{kN}\right)$ with the application of colloid solution

In the process of the DNP implementation, nanoparticles of tungsten were 'coined' into the specimen surface, because the density of newly formed dissipative structures was lower than that of the base material, and they extruded to the surface (Chausov, Volianska 2011). As a result, the hardness of the surface layer of the material within different sections of the specimen differed significantly, and possibilities were created for a sharp localization of the dissipative structure within the given working section of the material sample. 


\subsection{Titanium Alloy VT22}

In the course of testing aluminum alloys D16, 2024-T3 and stainless steel $04 \mathrm{Kh} 18 \mathrm{~N} 10$, the DNP was implemented in the plastic area of the statically pre-strained specimens. The major experiments with the DNP implementation in the heavy-duty titanium alloy VT22 were performed within the elastic section of the stress-strain curve. In this case, the total stress in the alloy caused by static pre-straining and impulse loading did not exceed the yield point of the alloy (Fig. 8).

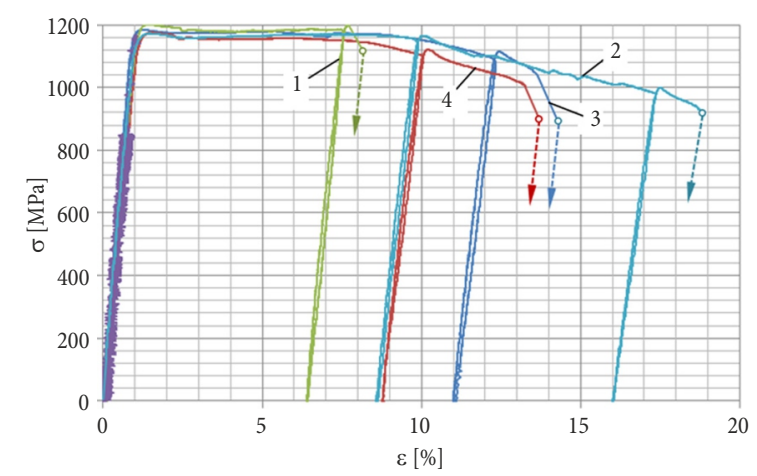

Fig. 8. Stress-strain curves for titanium alloy VT22: $1-\mathrm{ST}$; $2-\mathrm{ST}+\mathrm{DNP}\left(F_{i m p}=60 \mathrm{kN}\right)+\mathrm{ST} ; 3-\mathrm{HLN}+\mathrm{ST} ; 4-\mathrm{DNP}$ $\left(F_{i m p}=60 \mathrm{kN}\right)$ before the yield point of the alloy HLN $+\mathrm{ST}$

Let us consider the regularities in deformation and failure of alloy VT22:

- ST (curve 1, Fig. 8). The form of the curve indicates that the material has a high strength and low plasticity. Failure occurred at the longitudinal strain of 6.5\%;

- ST + DNP + ST (curve 2, Fig. 8) causes an increase in the longitudinal strain to $13.4 \%$ during failure;

- preliminary HLN of the alloy VT22 with subsequent warming up to $20^{\circ} \mathrm{C}$ leads to an increase in plasticity of the alloy, the failure strain is $14.2 \%$ (curve 3, Fig. 8);

- HLN after the DNP implementation within the elastic section of the stress-strain curve also enhances plasticity of the alloy, the failure strain is $13.8 \%$. However, the strength characteristics of the alloy decrease significantly (curve 4, Fig. 8). This can be associated with certain structural damage of the alloy and relevant residual increase in the volume after fragmentation (Zasimchuk et al. 2009; Hutsaylyuk et al. 2014).

Individual investigations into fracture surfaces of the alloy under different test patterns confirm that, in the case of formation of dissipative structures, the metal becomes non-uniform, i.e. some kind of a composite, in which there is alternation between soft zones (dissipative structure), hard zones (base material), and relevant layers between them. It is natural that energy expenditures on the growth of a macrocrack in such a hybrid material, as well as in the above-mentioned cases, must increase, which was observed in this work.
Thus, we were the first to achieve a significant increase in the initial plasticity of the material (alloy VT22) (practically by 2.75 times) due to the DNP implementation (Fig. 8).

\section{Discussion and Generalization}

To interpret the results obtained and describe the regularities obtained, we used additional methods of control of the material condition with a view to confirming the relationship between physical and mechanical phenomena that occur in the aviation alloys and stainless steels under investigation. Differences between the mechanisms of material deformation under the DNP are associated with significant fluctuations of the injection rate of energy into the material, due to which the specimen becomes agitated, and the surplus dissipates in local weakened zones.

\subsection{Using the $\mathrm{AE}$}

The condition of steel $04 \mathrm{Kh} 18 \mathrm{~N} 10$ was investigated using the method of AE under various test patterns (Vasyl'jev et al. 2012). A sensor-imitator, which emits AE signals of the preset shape and amplitude, was installed on the wide part of the flat test portion, and a similar sensor, which accepts AE signals, was installed at a fixed distance from the sensor-imitator. The signal velocity between the sensors was recorded along the flat surface of the specimen. At least 25-30 identical tests were performed for each condition of the material.

The results, which were obtained and generalized, are presented in Fig. 9 in the form of dependence of signal velocity imitated by the sensor-imitator on the degree of plastic deformation under the DNP implementation. The results obtained for steel $04 \mathrm{Kh} 18 \mathrm{~N} 10$ confirm the data obtained previously on a lower density of the dissipative structure formed after the DNP as compared to the base material.

The dissipative structure was found to extrude on the surface, and the elastic properties of the surface layer were found to be less than those of the initial material. In addition, the wave velocity decreased depending on the degree of plastic deformation under the DNP imple-

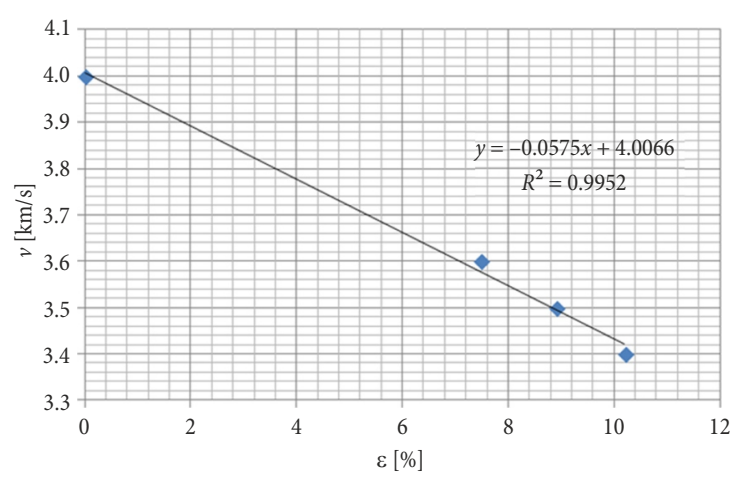

Fig. 9. Dependence of signal velocity of steel $04 \mathrm{Kh} 18 \mathrm{~N} 10$ emitted by the sensor-imitator on the degree of plastic deformation under the implementation of the DNP 
mentation. Moreover, the greater the degree of plastic deformation under the DNP implementation, the greater the volume of a newly formed dissipative structure. However, variations of the thin structure of the material are possible, as well as the accumulation of microdefects with an increase in the volume and localization of strain. A change in the strain rate from ST to DNP and the effect of HLN cause changes in relaxation processes in the metal structure and can lead to an increase in plastic deformation during further loading, or a coalescence of newly formed defects and subsequent failure of the specimen. The presence of inclusions and strengthening phases in the structure of steel $04 \mathrm{Kh} 18 \mathrm{~N} 10$ causes a decrease in the material plasticity after the DNP, i.e. a reverse effect.

\subsection{Aluminum Alloys D16 and 2024-T3}

Aluminum and titanium alloys are inclined to shortterm plastification with simultaneous 'abnormal' weakening due to the formation of amorphous dissipative structure in the form of localized bands volume bound at different scale levels, at which hydrodynamic yielding of the material occurs. However, shear strains in structural elements of the material are accompanied by changes in volume and depend on the DNP conditions.

Thus, a dissipative structure is formed due to the impulse injection of energy; moreover, the greatest part of the material within this new structure is subjected to the intensive compression (Chausov et al. 2015a). Most sensitive to such structural reconstructions of the material are the thermal capacity and the electrical resistance of the material (Omari, Sevostianov 2013; Sevostianov et al. 2010).

Structural changes, defect formation, and grain grinding affect the thermal capacity of the material, which will manifest itself indirectly while comparing the width of the initial specimens to those subjected to the DNP. Fig. 10 presents the results of the width measurements of specimens from the aluminum alloy 2024-T3 studied under different test patterns (Chausov et al. 2015a).

Significant differences between variations of the residual width of specimens were revealed, which are directly associated with different volumes of the broken structural elements of the alloy held in the medium of liquid nitrogen, and, respectively, different residual volumes of the specimen material (the presence of dispersed damage) after holding.

VT22. Measurement results of variation of the specimen width subjected to the DNP after HLN for one hour (curve 1, Fig. 11), as compared to the specimen in the initial condition (curve 2, Fig. 11), indicate a significant structural non-uniformity of alloy VT22.

Sections of residual stresses caused by the structural and mechanical changes and thermal fields occur in the material structure under the DNP. In the process of cooling, thermoelastic vibrations caused by the difference between the thermal capacities of the initial and modified layers are concentrated in them. The vibrations have a complex spatial morphological structure, which depicts the synergy of such collective self-organization phenomena as the mechanical yielding of material, dissipation processes, sharp changes in the dislocation density, etc. (Starke, Staley 1996).

The form of variation of the specimen width is one of the parameters that allows evaluating the material condition, since the newly created morphological structures are a result of the aggregation of the elementary stress relaxation acts. However, a high-quality analysis of the curve 1 (Fig. 11) and a high amplitude of vibrations indicate the presence of the zones with a significant strain capacity in the material.

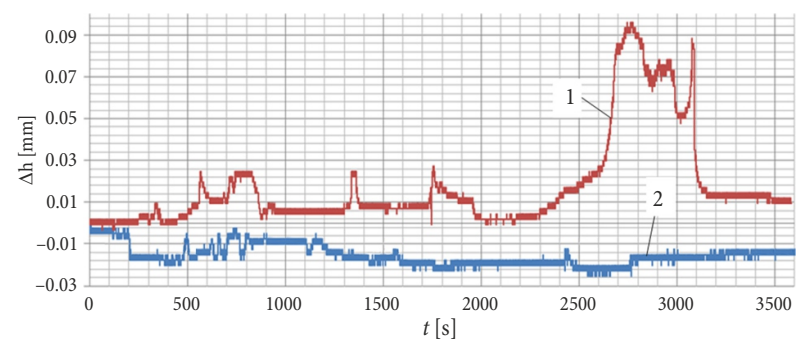

Fig. 11. Curves of variation of specimen width in the medium of liquid nitrogen (explanations are given in the text) a)

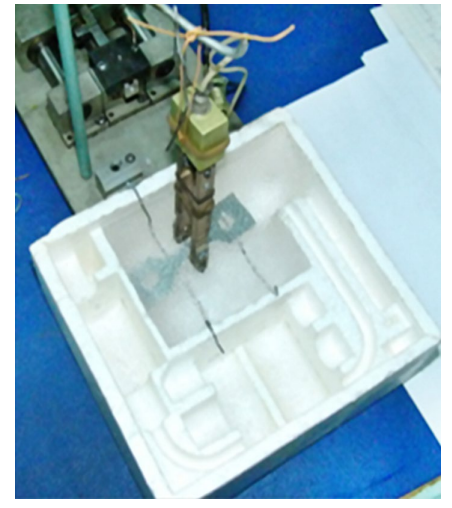

b)

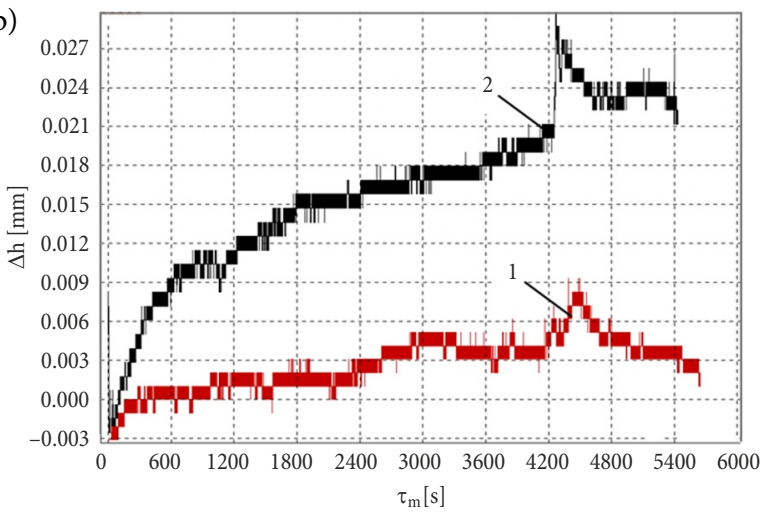

Fig. 10. Width measurement of specimens from the alloy 2024-T3 during HLN for 1 hour: a - specimen in a bath with liquid nitrogen; $\mathrm{b}$ - data on the specimen width variation ( 1 - initial condition; 2 - after the DNP implementation) 


\subsection{Fractographic analysis}

The comparative analysis of fracture surfaces of specimens from the titanium alloy VT22 investigated under different deformation modes testifies to the following. Regardless of the test pattern, a fracture surface has quite a smooth, structureless view. Torn-out sections of the material similar to 'shear lips' were found near the surface.
ST. The surface is formed by the ductile-brittle mechanism; it is covered with band-like scars oriented along the longest facet of the specimen, indicating the localization of the deformation process (Fig. 12a). The microrelief is formed by shallow, but clear-cut pits with a size of 1-3 $\mu \mathrm{m}$. Side surfaces of the pits are smooth, brittle, and have a view of spalling. Separation ridges have
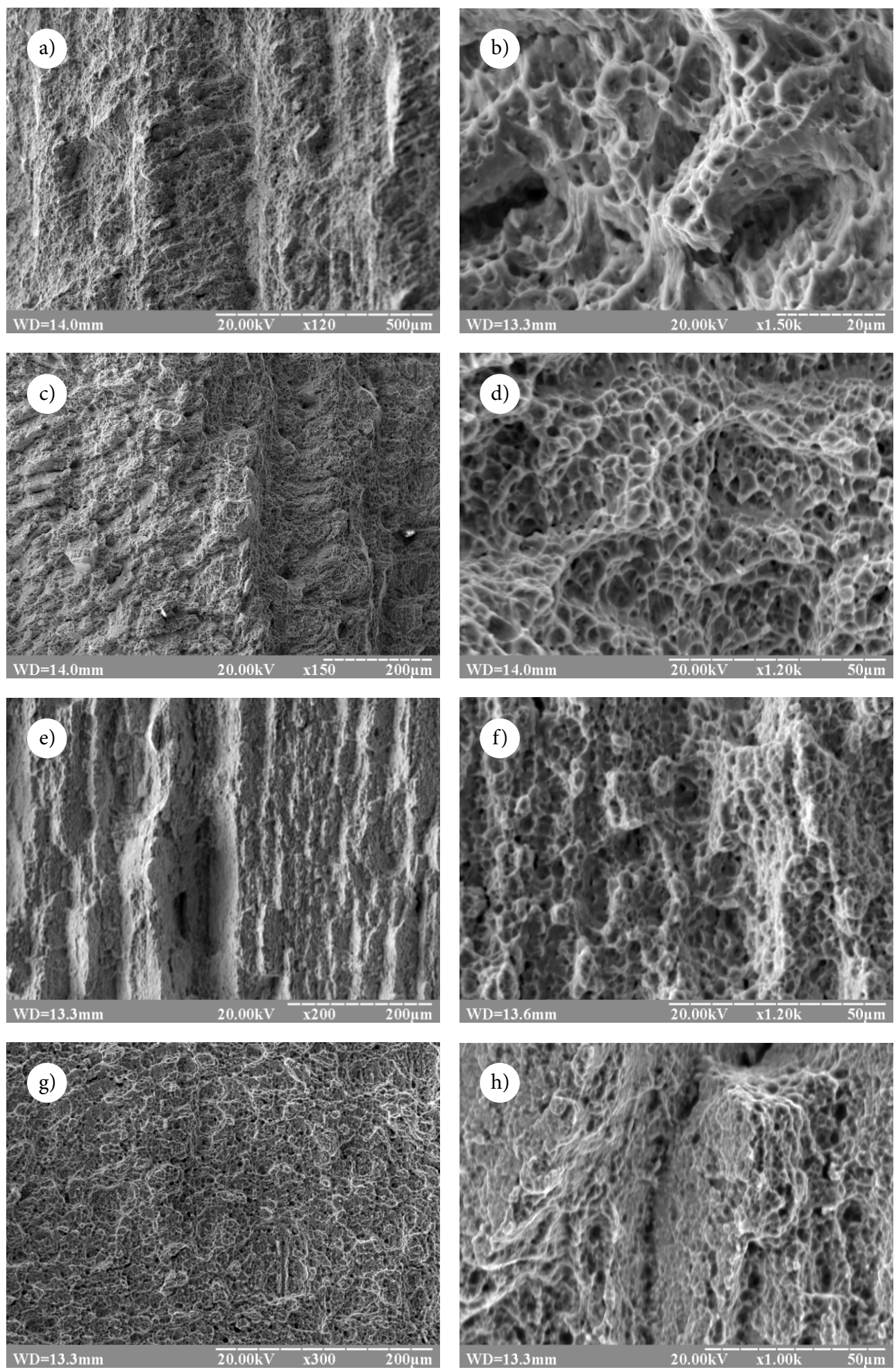

Fig. 12. Scanning Electron Microscope (SEM) images of fracture of alloy VT22 after: a, b - ST; c, d - ST + DNP $\left(F_{i m p}=60 \mathrm{kN}\right)+\mathrm{ST} ; \mathrm{e}, \mathrm{f}-\mathrm{HLN}+\mathrm{ST} ; \mathrm{g}, \mathrm{h}-\mathrm{DNP}\left(F_{i m p}=60 \mathrm{kN}\right)$ before the yield point of the alloy $+\mathrm{HLN}+\mathrm{ST}$ 
sharp edges, which indicate a brittle component in the process of material fracture (Fig. 12b).

$S T+D N P+S T$. At the macrolevel, the fracture surface is quite smooth and is covered with 'terraces' located parallel to the longest of the side facets (Fig. 12c). At a high magnification, some clear-cut circular pits are noticeable on the surface, which indicate a sufficient ductility of the material and high energy efficiency of its fracture. The size of pits is 5-7 $\mu \mathrm{m}$, in addition, it should be noted that they are all of nearly the same size, which indicates the graded nature of their formation and propagation, and a significant material plasticity (Fig. 12d).

$H L N+S T$. At the macrolevel, the fracture surface has two sections: a section of shear and a section of separation. Some 'banding' is also noticeable on the surface, indicating the presence of ridges located parallel to the largest of the specimen facets. The ridges are covered with micropits of size 2-4 $\mu \mathrm{m}$ with rough contours. The pits have a brittle view, and the mechanism of their formation can be described as ductile-brittle (Fig. 12e). They have a shape of a polyhedron, whose facets are associated with the formation of angles, at which the pit contours have the maximum thickness. Moreover, in contrast to the previous example, pits are located at several levels, i.e. on ridges and in valley sections (Fig. 12f).

DNP before the yield point of the alloy + HLN + $S T$. The specimen surface has two clear-cut sections - a section of ductile separation and a section of spalling (Fig. 12g). In the zone of ductile separation, the surface has a 'fibrous structure'. The fracture surface was formed in the ductile manner with the involvement of significant sections of the material in the process of deformation, which caused shear and rotation processes in the specimen cross-section. At the macrolevel, the fracture surface can be characterized as ductile-brittle; the fracture surface has a 'smoothed-out' view without any clear-cut pits or spalling (Fig. 12h).

The DNP implementation causes activation of the mechanisms of transverse sliding in the zone of strain localization, due to which even those phase components became active, in which low values of the energy of package defects impede the process of sliding (Yakovleva 2000; Maruschak et al. 2014; Okipnyi et al. 2014).

Using the methods of transmission electron microscopy, it was found that after additional force loading there is a significant fragmentation of the alloy, due to which small grains are formed in the base of the alloy ( $\beta$-phase), and the process of subgrain grinding takes place. In particular, the initial size of the base grain, which is $35-125 \mu \mathrm{m}$, decreased to $15-75 \mu \mathrm{m}$, and the size of subgrains decreased from $1.3-3 \mu \mathrm{m}$ to $0.6-3 \mu \mathrm{m}$. In the authors' opinion, it is the fine-grained structure of the alloy (with a high volume content) under the additional force loading that favours a significant increase in the initial plasticity of the alloy during further ST.

Let us formulate general regularities and certain technological recommendations, and technological peculiarities of using the DNP mode:

- the application of additional force loading of various classes during ST of specimens, as a rule, enhances their plasticity; under optimal values of the preliminary static deformation of a particular material and intense additional force loading, it is possible to achieve a significant increase in the initial plasticity of the material without any noticeable decrease in the strength characteristics;

- if impulse loads are applied before the yield point of the material, when the material damageability is minimal, the newly formed dissipative structure in the material volume is more uniform as compared to the dissipative structure, which is formed in materials at a significant level of plastic deformation, when the degree of the material damageability is much higher;

- to achieve an increase in plasticity, the presence of the DNP is an indispensable condition, however, insufficient; in this case, of paramount importance is the initial condition of the processed metal and the capacity of its structure for plastic deformation without the accumulation of multiple structural microdefects; in particular, the presence of inclusions and strengthening phases in the metal structure, a typical example of which is steel $04 \mathrm{Kh} 18 \mathrm{~N} 10$, causes a decrease in the material plasticity and activates the accumulation of structural damage after the DNP, i.e. provides for the reverse effect;

- fluctuations of loads lead to quick changes in the stress-strain state of the material, at which nonelastic strains in the material are determined not only by plastic deformation, but also by transformational deformation associated with phase transformations in the material; in addition, the process of modification is affected by HLN; the diffusion of alloying elements and the uniformity of their distribution depend, to a large extent, on the temperature and force conditions after the DNP, and have a determining influence on the properties of the aircraft materials (Nesterenko, B., Nesterenko, G. 2013; Ignatovich et al. 2013).

\section{Conclusions}

A complex study of the DNP process allowed finding the main regularities in the deformation behaviour of aviation steels and the steel of petrochemical equipment, as well as elaborating its mechanisms. In addition, an attempt was made to use the methods of non-destructive control and fractographic analysis to substantiate physical processes in the materials subjected to the DNP at the stages of their deformation and failure.

The DNP implementation in the aviation materials (alloys D16, 2024-T3, V22) at various stages of deformation causes a significant increase in their initial plasticity. However, a reverse effect was obtained for steel $04 \mathrm{Kh} 18 \mathrm{~N} 10$, and its plasticity decreased after the DNP.

Using the method of AE-scanning in the course of the DNP implementation, the previously obtained data on the extrusion of the newly created dissipative struc- 
tures on the surface of flat specimens due to their lower density, as compared to that of the base material, were confirmed.

It is confirmed, that the hybrid structure formed in the material in the course of the DNP implementation at a room temperature increases the material fracture toughness significantly at the same temperature. However, a sudden cooling of the material specimens after the formation of dissipative structures at a room temperature causes a significant concentration of defects on the boundaries between dissipative structures and the base material. This leads to the material embrittlement during further testing at a room temperature after warming.

A new mechanism of the formation of dissipative structures in the heavy-duty titanium alloy VT22 is found, which is associated with a local fragmentation of the initial structure under impact-oscillatory loading.

\section{References}

ASTM B209-14. Standard Specification for Aluminum and Aluminum-Alloy Sheet and Plate.

Chausov, M. G.; Berezin, V. B.; Pylypenko, A. P.; Hutsaylyuk, V. B. 2015a. Strain field evolution on the surface of aluminum sheet alloys exposed to specific impact with oscillation loading, Journal of Strain Analysis for Engineering Design 50(1): 61-72. https://doi.org/10.1177/0309324714548085

Chausov, M.; Maruschak, P.; Prentkovskis, O.; Pylypenko, A.; Berezin, V.; Volyanska, K. 2015b. Self-organisation of the heat resistant steel structure following dynamic non-equilibrium processes, Solid State Phenomena 220-221: 917-921. https://doi.org/10.4028/www.scientific.net/SSP.220-221.917

Chausov, M.; Maruschak. P.; Pylypenko, A.; Sergejev, F.; Student, O. 2012. Effect of high-force impulse loads on the modification of mechanical properties of heat-resistant steel after service, Estonian Journal of Engineering 18(3): 251-258. https://doi.org/10.3176/eng.2012.3.10

Chausov, M. H.; Volianska, K. M. 2011. Sposib lokalizacii' dysypatyvnoi' struktury $v$ materiali pry dynamichnyh nezrivnovazhenyh procesah [Method for localization of dissipative structure in materials at dynamical unstable processes]. Patent Ukrai'ny 97066. G01N 3/08. (in Ukrainian).

Dursun, T.; Soutis, C. 2014. Recent developments in advanced aircraft aluminium alloys, Materials \& Design 56: 862-871. https://doi.org/10.1016/j.matdes.2013.12.002

Gantois, K.; Morris, A. J. 2004. The multi-disciplinary design of a large-scale civil aircraft wing taking account of manufacturing costs, Structural and Multidisciplinary Optimization 28(1): 31-46. https://doi.org/10.1007/s00158-004-0427-7

GOST 19807-91. Titan i splavy titanovye deformiruemye. Marki. (in Russian).

GOST 4784-97. Aljuminij i splavy aljuminievye deformiruemye. Marki. (in Russian).

GOST 5632-72. Stali vysokolegirovannye i splavy korrozionnostojkie, zharostojkie i zharoprochnye. Marki. (in Russian).

Hutsaylyuk, V.; Chausov, M.; Berezin, V.; Pylypenko, A. 2013. Strength analysis of mechanical systems at dynamic nonequilibrium process, Engineering Failure Analysis 35: 636644. https://doi.org/10.1016/j.engfailanal.2013.06.005
Hutsaylyuk, V.; Chausov, M.; Berezin, V.; Pylypenko, A.; Volyanska, K. 2014. Influence of dissipative structures formed by impulsed loads on the processes of deformation and fracture, Key Engineering Materials 577-578: 273-276.

https://doi.org/10.4028/www.scientific.net/KEM.577-578.273

Ignatovich, S. R.; Menou, A.; Karuskevich, M. V.; Maruschak, P. O. 2013. Fatigue damage and sensor development for aircraft structural health monitoring, Theoretical and Applied Fracture Mechanics 65: 23-27. https://doi.org/10.1016/j.tafmec.2013.05.004

Jones, T.; Rustenburg, J. W.; Skinn, D. A.; Tipps, D. O.; DeFiore, T. 2005. Statistical Data for the Boeing-747-400 Aircraft in Commercial Operations. Final Report DOT/FAA/ AR-04/44. US Department of Transportation, Federal Aviation Administration. 244 p. Available from Internet: http:// www.tc.faa.gov/its/worldpac/techrpt/ar04-44.pdf

Kaufmann, M. 2008. Cost/Weight Optimization of Aircraft Structures: Licentiate Thesis. KTH School of Engineering Sciences, Stockholm, Sweden. 53 p.

Khantuleva, T. A.; Meshcheryakov, Y. I. 2016. Nonequilibrium processes in condensed media. Part 2. Structural instability induced by shock loading, Physical Mesomechanics 19(1): 69-76. https://doi.org/10.1134/S1029959916010070

Lebedev, A. A.; Chausov, N. G. 2004. Novye metody ocenki degradacii mehanicheskih svojstv metalla konstrukcij v processe narabotki: Monografija. Kiev. 133 s. (in Russian).

Lebedev, A. A.; Chausov, N. G.; Boginich, I. O.; Nedoseka, S. A. 1996. Systematic evaluation of the damage to a material during plastic deformation, Strength of Materials 28(5): 347-352. https://doi.org/10.1007/BF02330851

Lo, K. H.; Shek, C. H.; Lai, J. K. L. 2009. Recent developments in stainless steels, Materials Science and Engineering: $R$ : Reports 65(4-6): 39-104. https://doi.org/10.1016/j.mser.2009.03.001

Lytvynenko, I. V.; Maruschak, P. O. 2015. Analysis of the state of the modified nanotitanium surface with the use of the mathematical model of a cyclic random process, Optoelectronics, Instrumentation and Data Processing 51(3): 254263. https://doi.org/10.3103/S8756699015030073

Maruschak, P.; Menou, A.; Chausov, M.; Mocharskyi, V. 2014. Fractographic analysis of surface and failure mechanisms of nanotitanium after laser shock-wave treatment, Key Engineering Materials 592-593: 346-349.

https://doi.org/10.4028/www.scientific.net/KEM.592-593.346

Merati, A. 2005. A study of nucleation and fatigue behavior of an aerospace aluminum alloy 2024-T3, International Journal of Fatigue 27(1): 33-44.

https://doi.org/10.1016/j.ijfatigue.2004.06.010

Moiseev, V. N. 2000. High-strength titanium alloys for large parts of aircraft engines, Metal Science and Heat Treatment 42(2): 81-83. https://doi.org/10.1007/BF02469872

Nesterenko, B. G.; Nesterenko, G. I. 2013. A way to secure operational safety for an aircraft structure according to a strength criterion, Journal of Machinery Manufacture and Reliability 42(1): 62-75. https://doi.org/10.3103/S1052618813010093

Okipnyi, I. B.; Maruschak, P. O.; Zakiev, V. I.; Mocharskyi, V. S. 2014. Fracture mechanism analysis of the heat-resistant steel 15Kh2MFA(II) after laser shock-wave processing, Journal of Failure Analysis and Prevention 14(5): 668-674. https://doi.org/10.1007/s11668-014-9869-4 
Omari, M. A.; Sevostianov, I. 2013. Estimation of changes in the mechanical properties of stainless steel subjected to fatigue loading via electrical resistance monitoring, International Journal of Engineering Science 65: 40-48. https://doi.org/10.1016/j.ijengsci.2013.02.006

Ostash, O. P.; Andreiko, I. M.; Holovatyuk, Y. V. 2006. Degradation of materials and fatigue durability of aircraft constructions after long-term operation, Materials Science 42(4) 427-439. https://dx.doi.org/10.1007/s11003-006-0098-1

Shakleina, V. A.; Zamyatin, V. M. 2010. Inhomogeneity of plastic microdeformation in D16 aluminum alloy, Russian Engineering Research 30(5): 462-466. https://dx.doi.org/10.3103/S1068798X10050072

Sevostianov, I.; Zagrai, A.; Kruse, W. A.; Hardee, H. C. 2010. Connection between strength reduction, electric resistance and electro-mechanical impedance in materials with fatigue damage, International Journal of Fracture 164(1): 159-166. https://dx.doi.org/10.1007/s10704-010-9487-4

Smith, B. L.; Saville, P. A.; Mouak, A.; Myose, R. Y. 2000. Strength of 2024-T3 aluminum panels with multiple site damage, Journal of Aircraft 37(2): 325-331. https://dx.doi.org/10.2514/2.2597

Starke, E. A.; Staley, J. T. 1996. Application of modern aluminum alloys to aircraft, Progress in Aerospace Sciences 32(2-3) 131-172. https://doi.org/10.1016/0376-0421(95)00004-6

Vasyl'jev, O. S.; Gruzd, A. A.; Jolkin, A. O.; Krajevs'kyj, V. M.; Kushnyrenko, S. A.; Nedosjeka, A. Ja.; Nedosjeka, S. A.; Obodovs'kyj, B. M.; Fedchun, O. Ju.; Chausov, M. G.; Jaremenko, M. A. 2012. Desjatyrichnyj dosvid vprovadzhennja bezperervnogo akustyko-emisijnogo monitoryngu shovyshh amiaku Odes'kogo pryportovogo zavodu, Himichna promyslovist' Ukrainy 3: 43-51. (in Ukrainian).

Warren, A. S. 2004. Developments and challenges for aluminum - a Boeing perspective, in Aluminium Alloys Their Physical and Mechanical Properties: Proceedings of the 9th International Conference on Aluminium Alloys (ICAA9), 2-5 August 2004, Brisbane, Australia, 24-31.

Yakovleva, T. Y. 2000. Dislocation structure of VT22 titanium alloy in cyclic loading with various loading frequencies, Strength of Materials 32(4): 331-338. https://doi.org/10.1023/A:1026600617137

Zasimchuk, E. E.; Markashova, L. I.; Turchak, T. V.; Chausov, N. G.; Pylypenko, A. P.; Paratsa, V. N. 2009. Peculiarities of structural transformation in plastic materials under abrupt changes in loading conditions, Physical Mesomechanics 12(3-4): 175-179. https://doi.org/10.1016/j.physme.2009.07.010

Zherebtsov, S. V. 2012. Efficiency of the strengthening of titanium and titanium alloys of various classes by the formation of an ultrafine-grained structure via severe plastic deformation, Russian Metallurgy (Metally) (11): 969-974. https://doi.org/10.1134/S0036029512110146

Zholud, A. S.; Derbyshev, A. S.; Dulepov, Y. N. 2012. Use of corrosion-resistant steels and alloys in sulfuric acid media, Chemical and Petroleum Engineering 47(9-10): 627-631. https://doi.org/10.1007/s10556-012-9522-6 